\title{
A Combined Drug Treatment That Reduces Mitochondrial Iron and Reactive Oxygen Levels Recovers Insulin Secretion in NAF-1-Deficient Pancreatic Cells
}

\author{
Ola Karmi ${ }^{1}$, Yang-Sung Sohn ${ }^{1}$, Henri-Baptiste Marjault ${ }^{1}$, Tal Israeli ${ }^{2}$ (D) Gil Leibowitz ${ }^{2,3}$, \\ Konstantinos Ioannidis ${ }^{1,4}$, Yaakov Nahmias ${ }^{1,4}$, Ron Mittler ${ }^{5, *}$, Ioav Z. Cabantchik ${ }^{1, *}$ and Rachel Nechushtai ${ }^{1, *}$
}

Citation: Karmi, O.; Sohn, Y.-S.; Marjault, H.-B.; Israeli, T.; Leibowitz, G.; Ioannidis, K.; Nahmias, Y.; Mittler, R.; Cabantchik, I.Z.; Nechushtai, R. A Combined Drug Treatment That Reduces Mitochondrial Iron and Reactive Oxygen Levels Recovers Insulin Secretion in NAF-1-Deficient Pancreatic Cells. Antioxidants 2021, 10, 1160. https://doi.org/10.3390/ antiox10081160

Academic Editor: Davide Lauro

Received: 4 June 2021

Accepted: 19 July 2021

Published: 21 July 2021

Publisher's Note: MDPI stays neutral with regard to jurisdictional claims in published maps and institutional affiliations.

Copyright: (c) 2021 by the authors. Licensee MDPI, Basel, Switzerland. This article is an open access article distributed under the terms and conditions of the Creative Commons Attribution (CC BY) license (https:/ / creativecommons.org/licenses/by/ $4.0 /)$.
1 The Alexander Silberman Institute of Life Science, The Hebrew University of Jerusalem, Edmond J. Safra Campus at Givat Ram, Jerusalem 91904, Israel; ola.karmi@mail.huji.ac.il (O.K.); snjoshep@gmail.com (Y.-S.S.); henri.margault@mail.huji.ac.il (H.-B.M.); konstant.ioannidis@mail.huji.ac.il (K.I.); ynahmias.huji@gmail.com (Y.N.)

2 School of Medicine, The Hebrew University of Jerusalem, Jerusalem 9112102, Israel; tal.israeli@mail.huji.ac.il (T.I.); GLEIB@hadassah.org.il (G.L.)

3 Endocrinology and Metabolism Service, Hadassah Medical Center, Jerusalem 9112102, Israel

4 Alexander Grass Center for Bioengineering, The Hebrew University of Jerusalem, Edmond J. Safra Campus at Givat Ram, Jerusalem 91904, Israel

5 Department of Surgery, University of Missouri School of Medicine, Columbia, MO 65201, USA

* Correspondence: mittlerr@missouri.edu (R.M.); ioav.caban@mail.huji.ac.il (I.Z.C.); rachel@mail.huji.ac.il (R.N.)

Abstract: Decreased insulin secretion, associated with pancreatic $\beta$-cell failure, plays a critical role in many human diseases including diabetes, obesity, and cancer. While numerous studies linked $\beta$-cell failure with enhanced levels of reactive oxygen species (ROS), the development of diabetes associated with hereditary conditions that result in iron overload, e.g., hemochromatosis, Friedreich's ataxia, and Wolfram syndrome type 2 (WFS-T2; a mutation in CISD2, encoding the [2Fe-2S] protein NAF-1), underscores an additional link between iron metabolism and $\beta$-cell failure. Here, using NAF1-repressed INS-1E pancreatic cells, we observed that NAF-1 repression inhibited insulin secretion, as well as impaired mitochondrial and ER structure and function. Importantly, we found that a combined treatment with the cell permeant iron chelator deferiprone and the glutathione precursor $\mathrm{N}$-acetyl cysteine promoted the structural repair of mitochondria and ER, decreased mitochondrial labile iron and ROS levels, and restored glucose-stimulated insulin secretion. Additionally, treatment with the ferroptosis inhibitor ferrostatin-1 decreased cellular ROS formation and improved cellular growth of NAF-1 repressed pancreatic cells. Our findings reveal that suppressed expression of NAF-1 is associated with the development of ferroptosis-like features in pancreatic cells, and that reducing the levels of mitochondrial iron and ROS levels could be used as a therapeutic avenue for WFS-T2 patients.

Keywords: NAF-1 (CISD2); oxidative stress; iron hemostasis; Wolfram syndrome type 2 (WFS-T2); ferroptosis; insulin secretion

\section{Introduction}

Wolfram Syndrome Type 2 (WFS-T2) is a rare genetic disease found in several different populations worldwide [1-7]. Its early onset is characterized by severe insulin deficiency leading to juvenile onset of diabetes mellitus, progressive appearance of gastro-intestinal (GI) ulcers, abnormal platelet aggregation, sensorineural hearing loss, optical nerve atrophy, and psychosis [1,8-11]. A number of different studies identified the CISD2 gene as the causative agent of WFS-T2, with several different mutations in the CISD2 allele associated with different forms of WFS-T2 [1-4,6,7]. Most of the mutations in the CISD2 gene, leading to WFS-T2, resulted in a complete or partial loss of the NAF-1 (Nutrient-deprivation 
Autophagy Factor-1) CISD2 protein, a protein that normally resides on the endoplasmic reticulum (ER), the outer mitochondrial membrane (OMM), and the mitochondria-ERassociated membranes (MAM) [12]. Interactome studies of NAF-1, a member of the [2Fe-2S] NEET protein family [13], implicated this protein in the regulation of autophagy and apoptosis, and added support to the empirical evidence associating NAF-1 with dysfunctional iron metabolism, ROS formation, and $\mathrm{Ca}^{2+}$ signaling at the ER and mitochondria [13-15]. The association of NAF-1 function with altered iron and ROS metabolism gained further support from studies conducted in cancer cells [14,16-24]. These studies reveal that cancer cells accumulate high levels of NAF-1, and that disrupting NAF-1 function, for example by a point mutation in the NAF-1 [2Fe-2S] cluster-binding domain, or by suppressing NAF-1 protein expression using shRNA, results in enhanced levels of mitochondrial labile iron and ROS levels that trigger apoptosis of cancer cells [14,16,18,22,24].

The studies described above suggest a tight association between NAF-1 protein level and/or function and the protection of cells from overaccumulation of iron and ROS in their mitochondria (a form of ferroptosis, as was shown for cells with reduced expression of mitoNEET, a different member of the NEET protein family; $[25,26])$. Based on this potential relationship, we hypothesized that treatments that can reduce the levels of iron and ROS in the mitochondria of WFS-T2 patients could ameliorate some of the cell dysfunctions (biochemical and physiological) associated with NAF-1 deficiency in these patients. To begin addressing our hypothesis, we established an insulinoma INS-1E pancreatic $\beta$-cell model of NAF-1 stable repression (by gene Knock Down; KD; referred to here as NAF-1(-)), whereby structural and functional properties resulting from NAF-1 gene repression are demonstrably reversed by overexpressing the normal gene. We then assessed to what extent the elevated mitochondrial labile iron (mLI) and ROS (mROS) observed in NAF-1(-) insulinoma cells contributed to impaired stimulated insulin secretion, and whether alleviating $\mathrm{mLI}$ and $\mathrm{mROS}$ accumulation will improve glucose-stimulated insulin secretion. Here, we show that suppressed expression of NAF-1 in INS-1E pancreatic $\beta$-cells results in the appearance of ferroptosis-like features that include enhanced lipid peroxidation, enhanced $\mathrm{mROS}$ and $\mathrm{mLI}$ levels, shrunken mitochondria, decreased expression of glutathione peroxidase 4 (GPX4), and enhanced expression of transferrin receptor (TfR). We further show that an anti-ferroptosis treatment based on the combined action of the membrane permeant iron chelator deferiprone (DFP; $[27,28]$ ) and the glutathione precursor $\mathrm{N}$-acetyl cysteine (NAC; [29-31]), significantly ameliorated mitochondrial labile iron and ROS levels and mitochondrial and ER structural abnormalities, as well as repairing insulin secretion of NAF-1 repressed cells. In addition, we found that treatment with the ferroptosis inhibitor ferrostatin-1 $[25,32,33]$ decreased cellular ROS formation and improved cellular growth of NAF-1(-) INS-1E pancreatic cells. Our findings suggest that targeting ferroptosis of pancreatic cells could be used as a clinical strategy in the treatment of WFS-T2 patients.

\section{Materials and Methods}

\subsection{Cell Growth and NAF-1 Expression}

INS-1E $\beta$-cells were grown as previously described [11]. Plasmids containing shRNA in pGFP-RS vector (OriGene Technologies, Inc., Rockville, MD, USA) were used for repressing NAF-1 expression, whereas plasmids containing the pEGFP-N1 vector (Clontech Laboratories, Inc. Mountain View, CA, USA) were used for over-expressing NAF-1. Cell growth and transfection were performed as described earlier $[16,18]$. Three independent stable transfected lines were generated for each construct and transfection and used as different biological controls.

\subsection{Protein Blots}

For protein blot analyses, cells were grown to full confluence, washed twice with $1 \mathrm{X}$ PBS and immediately scraped off the plate into a microcentrifuge tube with 1X Laemmli sample buffer and heated to $95{ }^{\circ} \mathrm{C}$ for $10 \mathrm{~min}$. Protein gels were loaded with equal amounts of proteins and analyzed using antibodies against NAF-1 [11,16], Anti-TXNIP 
(Cell signaling technology, D5F3E), Anti-Thioredoxin 2 antibody (Abcam, [EPR15225] ab185544), Anti-actin (Sigma, MAB1501), Anti-IRE1 antibody (Abcam, ab37073), AntiIRE1 (phospho S724) antibody (Abcam, [EPR5253] ab124945), anti-Mitofusin 2 antibody (Abcam, [6A8] ab56889), Anti-Glutathione Peroxidase 4 (GPX4) antibody (R\&D Systems, Biotechne, MAB5457), and Anti-Transferrin Receptor Antibody (Abcam, ab84036). Goat Anti-Rabbit IgG, H\&L Chain Specific Peroxidase Conjugate (Sigma, 401315) and Peroxidaseconjugated AffiniPure Goat anti-mouse IgG $(\mathrm{H}+\mathrm{L})$ (Jack-son ImmunoResearch Laboratories, AB_10015289) were used as secondary antibodies $[7,24]$.

\subsection{Lipid Peroxidation}

Malondialdehyde (MDA) was measured using QuantiChrome TBARS Assay Kit (DTBA-100, BioAssay Systems, Hayward, CA, USA) according to the manufacturer's instructions. Briefly, cells $\left(5 \times 10^{6}\right)$ were harvested, homogenized in ice cold PBS buffer, and disrupted by sonication. Cell lysates were incubated with ice-cold $10 \%$ trichloroacetic acid and centrifuged for $5 \mathrm{~min}$ at 14,000 rpm. After the neutralization, the clear sample supernatant was mixed with thiobarbituric acid (TBA) solution and incubated at $100{ }^{\circ} \mathrm{C}$ for $60 \mathrm{~min}$. Fluorometric assay was used for quantitative determination of lipid peroxides (thiobarbituric acid reactive substances, TBARS); this was evaluated using the Perkin Elmer EnVision 2104-0020 Multilabel Plate Reader at Ex/Em 530/550 nm.

\subsection{Fluorescence Probes}

Cells were cultured and imaged by epi-fluorescent microscopy for their mitochondrial labile iron (mLI) with the fluorescent probe RPA (rhodamine B-[(1,10-phenanthrolin-5yl) aminocarbonyl] benzyl ester) (Squarix biotechnology, ME043.1, Marl, Germany), as described in [16]. Mitochondrial ROS accumulation was determined using mitoSOX ${ }^{\mathrm{TM}}$ Red (Invitrogen ${ }^{\mathrm{TM}}$, M36008, Massachusetts, USA), according to [18,34]. For protein carbonylation measurements, $\mathrm{CH}$ (Coumarin Hydrazine) (Cayman Chemical, 113707-87-2, Michigan, USA) was added at $20 \mu \mathrm{M}$, and fluorescence images were acquired and analyzed (excitation $365 \mathrm{~nm}$, emission 430-550 nm) [35]. For mitochondrial membrane potential (MMP), we used TMRE (tetramethylrhodamine ethyl ester) (Sigma, 87917, Missouri, USA) at a concentration of $0.1 \mu \mathrm{M}$. Fura Red ${ }^{\mathrm{TM}}, \mathrm{AM}$, cell permeant (Invitrogen ${ }^{\mathrm{TM}}, \mathrm{F} 3020$ ) was used to measure cytosolic $\mathrm{Ca}^{2+}$ by exposing cells to $4 \mu \mathrm{M}$ for $40 \mathrm{~min}$ at $37^{\circ} \mathrm{C}$, in the presence of $0.02 \%$ Pluronic ${ }^{\circledR}$ F-127 (Sigma, P2443). Images were analyzed with Volocity (Quorum Technologies Inc. Puslinch, ON, Canada) and/or with Image-J. Quantification of fluorescence was performed using 30 different fields ( 5 cells per field). Quantification of mito-SOX ${ }^{\mathrm{TM}}$ fluorescence changes was performed by analyzing 9 different fields ( 5 cells per field) and averaged for 3 independent experiments. For all fluorescence imaging studies, different cells were plated onto microscope slides glued to perforated $3 \mathrm{~cm}$ diameter tissue culture plates, as previously described [16,34]. For Glutathione levels detection, ThiolTracker ${ }^{\mathrm{TM}}$ Violet (glutathione detection reagent) (Invitrogen $\left.{ }^{\mathrm{TM}}, \mathrm{T} 10095\right)$ was used at $20 \mu \mathrm{M}$ for $30 \mathrm{~min}$ at $37^{\circ} \mathrm{C}$, then measured using an Olympus FV3000 confocal laserscanning. For cell viability, cells were seeded in 96-well plates in triplicates at a density of 2000 cells/well. PrestoBlue ${ }^{\mathrm{TM}}$ Cell Viability Reagent (Invitrogen ${ }^{\mathrm{TM}}$, A13261) was used to determine cell viability on days 1,4 , and 7 with or without the addition of ferrostatin-1. Fluorescence was measured on a plate reader after $2 \mathrm{~h}$ of incubation at $37^{\circ} \mathrm{C}$ (excitation, $560 \mathrm{~nm}$, emission, $590 \mathrm{~nm}$ ). For cell ROS measurements, CellROX ${ }^{\mathrm{TM}}$ Deep Red Reagent detection assay (Invitrogen ${ }^{\mathrm{TM}}, \mathrm{C} 10422$ ) was used in conjunction with a Biotek plate reader (excitation $640 \mathrm{~nm}$, emission $665 \mathrm{~nm}$ ). For Mitochondrial-ER contact fluorescence imaging, cells were transfected with pDsRed2-ER plasmid to give the ER fluorescence signal, then cells were treated with the mitochondrial tracker Rhodamine 800 (Sigma, 83701). Nuclei were stained with bisBenzimide H 33,342 trihydrochloride (Sigma, 14533). Cells were then evaluated by the Olympus FV3000 confocal laser-scanning microscope, and all images were analyzed with image $\mathrm{J}$. 


\subsection{Treatment of Cells with Ferrostatin-1, the Iron Chelator (DFP), and the Glutathione Precursor CGP (NAC)}

Cells were incubated with or without ferrostatin-1 (3-Amino-4-cyclohexylaminobenzoic acid ethyl ester) (Sigma, Product No. SML0583), using a concentration of $2 \mu \mathrm{M}$, for the entire experiment period. Cells were also incubated with or without DFP (3-Hydroxy-1,2dimethyl-4(1H)-pyridone) (Sigma, 379409). The proper concentration was optimized for each cell type and controls; DFP was added at $100 \mu \mathrm{M}$ for $2 \mathrm{~h}$ to cells for mLI and mROS quantifications $[11,16]$. Cells were treated with/without the cellular glutathione precursor (CGP) (NAC) (N-Acetyl-L-Cysteine) (Sigma, Product No. A7250-10G) antioxidant. Pretreatment was optimized to $100 \mu \mathrm{M}$ for $2 \mathrm{~h}$, for the experiments of mLI and mROS levels [36-38]. In the experiments of insulin secretion and TEM, the DFP concentration used was $50 \mu \mathrm{M}$ and the NAC concentration used was $100 \mu \mathrm{M}$, overnight.

\subsection{Mitochondrial Bioenergetics, Oxygen Consumption Rate (OCR), Cellular Glycolysis, and Extracellular Acidification Rate (ECAR)}

OCR and ECAR were measured using a Seahorse XFp, Agilent, cell mito-stress analyzer (Agilent Technologies, Inc., Santa Clara, CA, USA) with the XF Cell Mito Stress Kit and XF Glycolysis Stress Kit (Agilent Technologies, Inc., Santa Clara, CA, USA), according to the manufacturer's instructions [39]. INS-1E $\beta$-cells $(30,000)$ were grown to approximately $80 \%$ confluence in complete medium, $48 \mathrm{~h}$ before experiment. The initial medium was then exchanged with a seahorse-running medium consisting of Dulbecco's Modified Eagle's Medium (DMEM) base without glucose, L-Glutamine $2 \mathrm{mM}$, sodium pyruvate $1 \mathrm{mM}$, with glucose added to a final concentration of $25 \mathrm{mM}$ and $\mathrm{pH}$ adjusted to be 7.3-7.4. Then, microplates containing cells were incubated at $37^{\circ} \mathrm{C}$ without $\mathrm{CO}_{2}$ for $1 \mathrm{~h}$ before the assay. Plates were then placed into the XFp analyzer. The OCR was calculated after the sequential additions of oligomycin A $1 \mu \mathrm{M}$, FCCP $10 \mu \mathrm{M}$, antimycin A/Rotenone $0.5 \mu \mathrm{M}$, using an XF Cell Mito Stress Test kit. The ECAR medium initially did not contain glucose, and was then measured after the addition of glucose $25 \mathrm{mM}$. The results were expressed as mean $\pm \mathrm{SD}$ of three independent experiments. All measurements were recorded at set-interval time points. All materials and compounds were obtained from Seahorse Bioscience [16]. Calculations of the OCR and the ECAR test parameters were performed according to the manufacturer recommendations, using the equations described in [39].

\subsection{Insulin Secretion Measurement}

Cells were plated in 24-well plates $48 \mathrm{~h}$ before insulin stimulation with high glucose concentration, as described in [11]. Cells were pre-incubated with a low glucose containing a medium of $1.7 \mathrm{mM}$ after which basal insulin concentration was measure. Then, stimulation was determined after pre-incubation with high glucose $(16.7 \mathrm{mM})$, as described in [11]. Insulin secretion was measured by the insulin ELISA kit (Mercodia, Uppsala, Sweden, 10-1250-01), then calculated as fold from the basal insulin concentration.

\subsection{Mitochondria and ER Structure}

Cells were grown on 8-well Permanox chamber slides and, upon reaching approximately $80 \%$ confluence, were fixed in $2.5 \%$ glutaraldehyde and $2 \%$ paraformaldehyde in $0.1 \mathrm{M}$ cacodylate buffer ( $\mathrm{pH}$ 7.4) for $2 \mathrm{~h}$ at room temperature, then prepared for Transmission Electron Microscope (TEM) imaging, as described in detail in [16]. The results were evaluated from 5-10 different cells randomly selected, averaged over 10-20 fields per cell; at least 100-200 mitochondria and 200-300 ER were counted. Mitochondrial and ER damages were expressed as the ratio of damaged organelle to total number of the organelle, in three independent experiments [16]. Mitochondrial length was similarly determined in three different biological repeats [16]. 


\subsection{Statistics}

Statistical significance tests (Student's $t$-test) for protein expression, insulin measurements, and analysis of epi-fluorescent microscope and TEM images were performed using GraphPad Prism 8.3.1 software. The results are presented as box-and-whisker plots and include all measured data points; the line inside the box represents the median, the box represents the interquartile range, and the whiskers represent the range. Differences were statistically significant if the Student's $t$-test produced a probability value of less than $5 \%$ $\left({ }^{*} p<0.05 ;{ }^{* *} p<0.01 ;{ }^{* * *} p<0.001\right)$.

\section{Results}

\subsection{NAF-1-Suppressed Insulinoma Cells as a Model for Pancreatic $\beta$-Cells of WFS-T2}

We selected the murine insulinoma INS-1E cells for assessing the consequences of NAF1 deficiency on pancreatic $\beta$-cells of WFS-T2 primarily on the basis that these cells respond to glucose stimuli by secreting insulin. Following NAF-1 shRNA transfection, we selected 3 independent stable clones of INS-1E cells expressing 50\% lower levels of the NAF-1 protein compared with WT control (Figure 1A). Importantly, these NAF-1(-) cells showed a commensurately lower glucose-stimulated insulin secretion ability compared with normal cells (Figure 1B) and a 2.5-fold increase in the level of the thioredoxin-interacting protein (TXNIP) (but not thioredoxin (TRX)) (Figure 1C). TXNIP and TRX play antagonistic roles in $\beta$-cell function and diabetes pathophysiology, and accumulation of TXNIP in insulinoma cells is typically a sign of oxidative stress [40-42]. To ascertain that the changes in cell functions are attributable to a reduction in NAF-1 per se, control WT and NAF-1(-) cells were further transfected with WT NAF-1, referred to here as NAF-1(+) and NAF-1 $(-/+)$, respectively ( 3 independent stable clones for each vector were generated). As shown in Figure 1, the repressed expression of NAF-1, as well as glucose-stimulated insulin secretion and the enhanced expression of TXNIP in NAF-1(-) INS-1E cells could be significantly reversed by transfection of NAF-1(-) cells with the WT NAF-1 gene.

\subsection{Mitochondrial, ER, and MAM Structural Changes in NAF-1(-) Cells}

NAF-1(-) cells displayed various abnormalities in mitochondria size, cristae integrity, and ER structure (Figure 2A), possibly as a result of ER stress, as suggested by the increased expression of phosphorylated IRE-1 expression (Figure 2B), an important component of the unfolded protein response (UPR). Moreover, the number of membranal contacts between mitochondria and ER (MAMs) decreased, suggesting fewer interactions between mitochondria and the ER through these structures (Figures 2A and 3A). This reduced tethering was further supported by measuring the levels of mitofusin 2 (MFN2; [43-45]), a protein implicated in the maintenance of MAM integrity (Figure 3B). Importantly, mitochondrial, ER, and MAM abnormalities found in NAF-1(-) cells were largely corrected upon re-expression of WT NAF-1 in NAF-1(-) cells (Figures 2 and 3). 


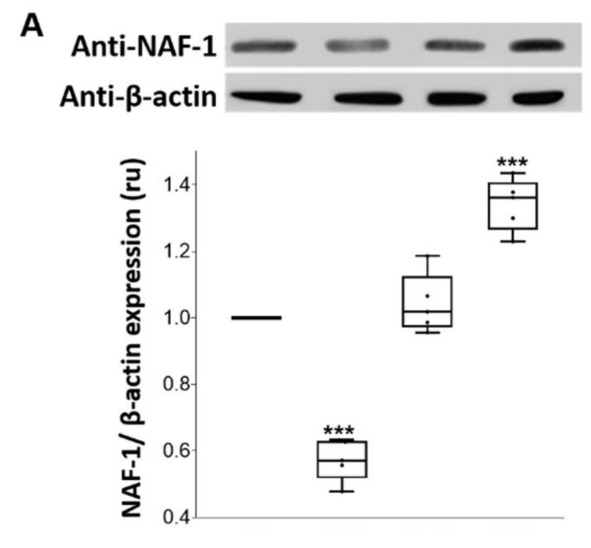

B

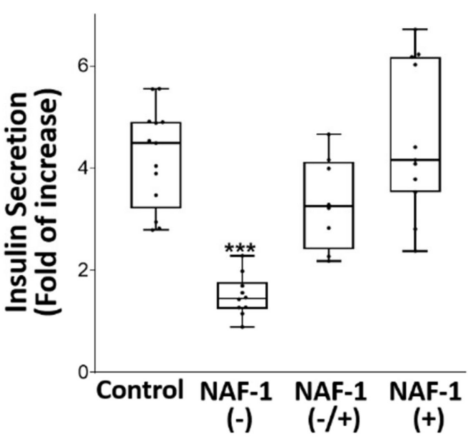

C

Anti- TXNIP

Anti- TRX

Anti- $\beta$ - actin

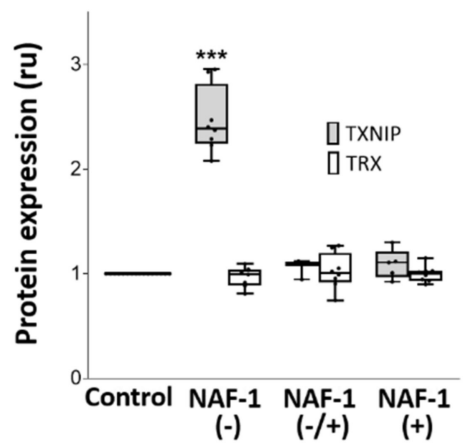

Figure 1. NAF-1 protein levels, insulin secretion, and TXNIP expression in INS-1E cells with repressed or overexpressed NAF- 1 levels. (A) Protein blots (Top) and $\beta$-actin-normalized expression graph (Bottom) showing NAF-1 protein levels in control, NAF-1(-), NAF-1 $(-/+)$, and NAF-1(+) cells. (B) Fold change in glucose-stimulated insulin secretion of INS-1E cells expressing different levels of NAF-1. (C) Protein blots (Top) and $\beta$-actin-normalized expression graph (Bottom) showing TXNIP and TRX protein levels in INS-1E cells expressing different levels of NAF-1. The results are presented as box-and-whisker plots and include all data points measured in three different experiments. *** $p<0.001$, compared to control; Student's $t$-test, $N=3$. Abbreviations: TRX, Thioredoxin; TXNIP, Thioredoxin-interacting protein. 

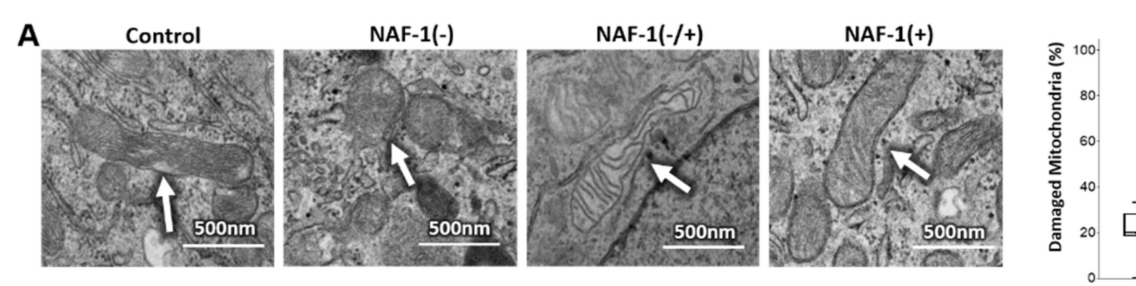

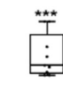
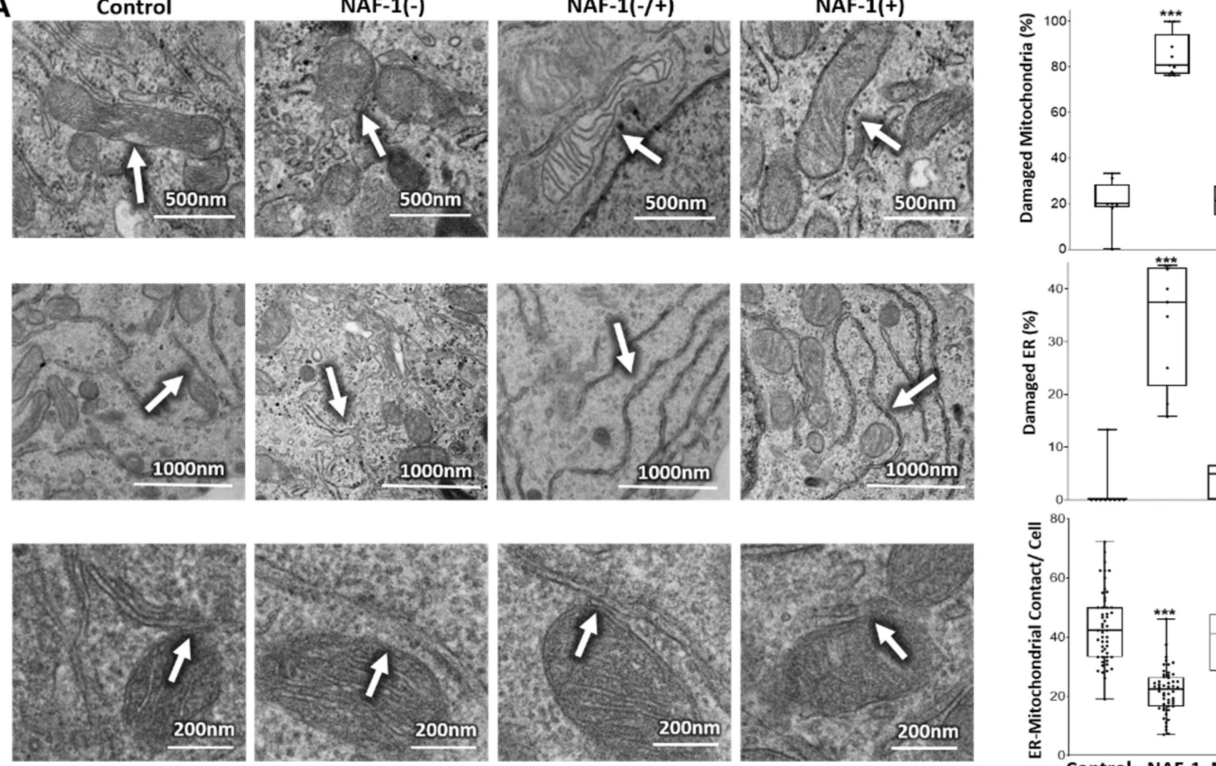

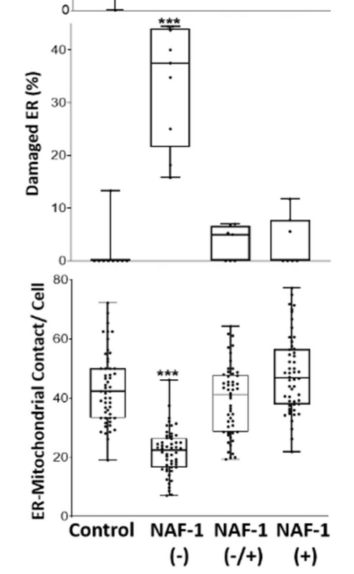

B

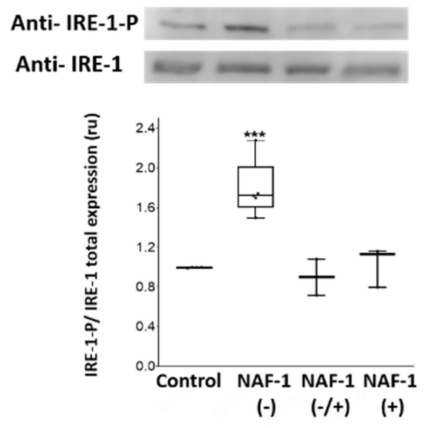

Figure 2. Mitochondrial and ER structural alterations and phosphorylation of IRE-1 in INS-1E cells with repressed or overexpressed NAF-1 levels. (A) Representative TEM images (left panels) and statistical analysis (right graphs) of alterations in mitochondrial (top), ER (middle), and ER-mitochondrial contact points (bottom) structures in control, NAF-1(-), NAF$1(-/+)$, and NAF-1(+) cells. (B) Protein blots (top) and graph (bottom) showing the ratio between IRE-1 and phosphorylated IRE-1 (IRE-1P) in INS-1E cells expressing different levels of NAF-1. The results are presented as box-and-whisker plots and include all data points measured in three different experiments. ${ }^{* * *} p<0.001$, compared to control; Student's $t$-test, $\mathrm{N}=600$ for mitochondria and mitochondrial-ER contact and $\mathrm{N}=900$ for ER. Abbreviations: IRE, serine/threonine-protein kinase/endoribonuclease.

\subsection{Biochemical and Physiological Changes in NAF-1(-) Cells}

To determine whether the structural changes observed in NAF-1(-) INS-1E (Figures 2 and 3) were accompanied by biochemical and physiological changes in mitochondrial function, we measured mitochondrial respiration, ATP production, $\mathrm{mLI}$, and mROS in NAF-1(-) cells. A significant reduction ( $40 \%)$ in mitochondrial functions of NAF-1 repressed cells was observed in mitochondrial maximal respiratory capacity, an indicator of functional mitochondrial mass (Figure 4A), cell respiration (Figure 4B), and ATP production (Figure 4C); all indicative of depleted mitochondrial reserves. Restoration of NAF-1 expression to wildtype levels commensurately restored these affected functions. By contrast, extracellular acidification rate (ECAR) of NAF-1(-) did not significantly change, suggesting that, at least in INS-1E cells, a deficiency in NAF-1 levels does not impact glycolysis (Figure S1). In this respect, insulinoma cells are different from epithelial breast cancer cells in which glycolysis was activated upon NAF-1 protein suppression [34]. In addition to its effect on mitochondrial respiration (Figure 4), the reduced expression of NAF-1 led to an increase in mitochondrial labile iron (mLI) (Figure 5A), a rise in the levels of mitochondrial ROS (mROS) (Figure 5B), and an increase in protein carbonylation levels (Figure 5C). Similar to our findings described above for mitochondrial structure and function (Figures 2-4), restoration of NAF-1 expression to wildtype levels commensurately restored mLI, mROS, and protein carbonylation levels to near WT levels (Figure 5). Additional changes that were restored by recovering the expression of NAF-1 in NAF-1(-) cells were changes in mitochondrial membrane potential (MMP; Figure S2), and cytosolic $\mathrm{Ca}^{2+}$ levels (Figure S3). 

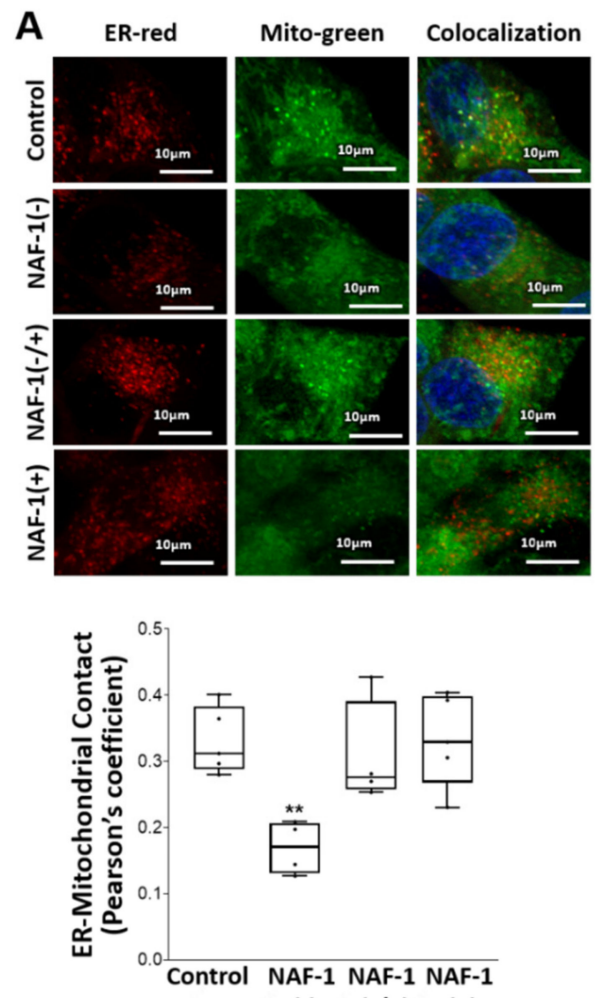

B

$(-) \quad(-/+) \quad(+)$

\section{Anti-MFN2}

Anti- $\beta$-actin

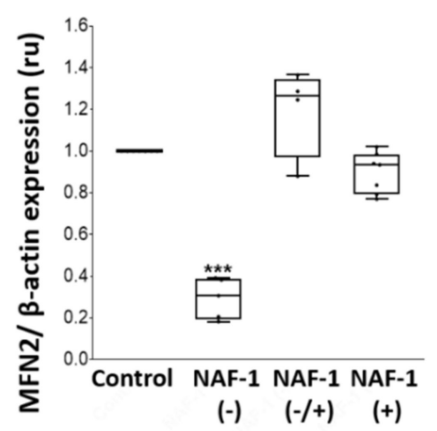

Figure 3. Quantification of ER-mitochondrial contacts using confocal microscopy and expression of MFN2 in INS-1E cells with repressed or overexpressed NAF-1 levels. (A) Representative confocal images of INS-1E control, NAF-1(-), NAF-1(+), and NAF-1(-/+) cells co-expressing an ER-, mitochondria- and nucleus-targeted red, green, and blue fluorescent proteins, respectively (top). Yellow (green-red merged fluorescence) denotes contact points between the ER and the mitochondria. Quantification graphs showing the number of ER-mitochondrial contact points per cell (bottom). (B) Protein blots (top) and $\beta$-actin-normalized expression graph (bottom) showing MFN2 protein levels in INS-1E cells expressing different levels of NAF-1. The results are presented as box-and-whisker plots and include all data points measured in three different experiments. ${ }^{* *} p<0.01,{ }^{* * *} p<0.001$, compared to control; Student's $t$-test, $N=50$. Abbreviations: MFN2, mitofusin 2. 
A

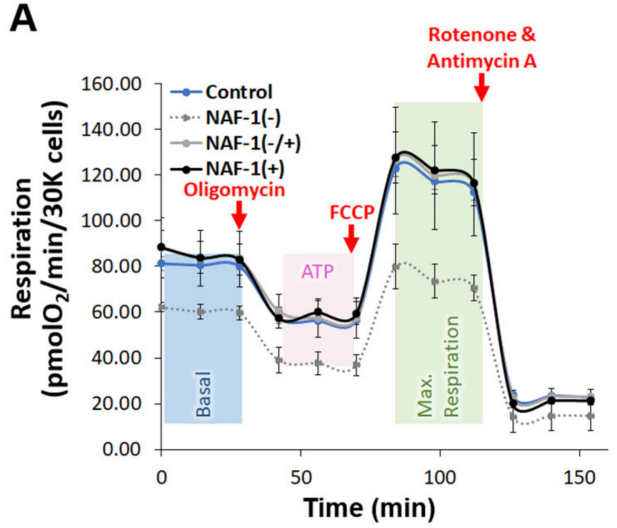

B

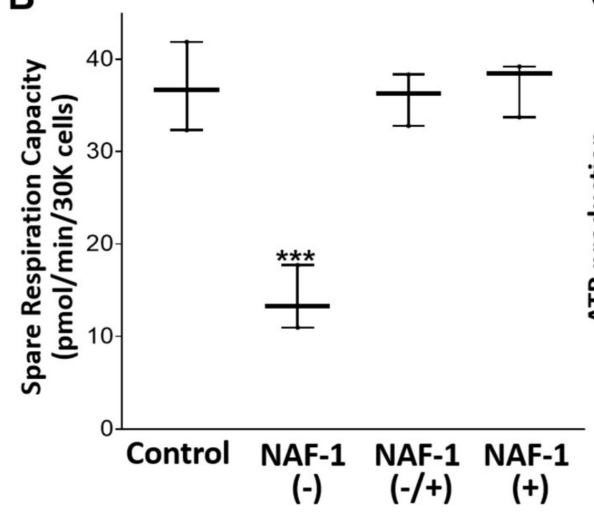

C

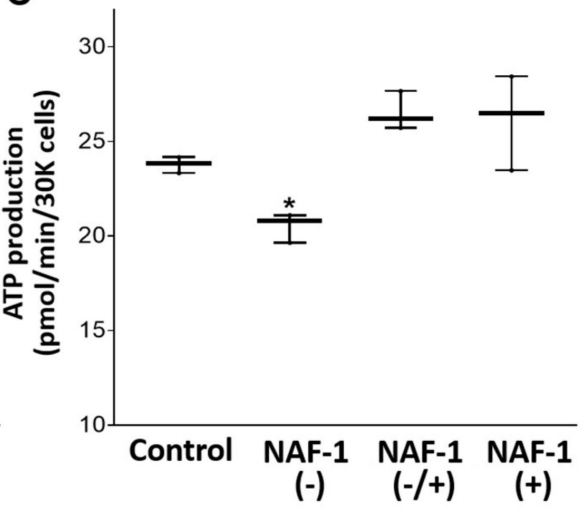

Figure 4. Mitochondrial respiration and ATP production in INS-1E cells with repressed or overexpressed NAF-1 levels. (A) Seahorse-generated plots of mitochondrial respiration obtained for the different lines. Data are presented in normalized values. (B) Spare respiratory capacity calculated from (A). (C) ATP levels calculated from (A). Results in (A) were normalized to the number of cells used $(30,000)$. Data in $(\mathbf{B}, \mathbf{C})$ are presented as box-and-whisker plots and include all data points measured in three different experiments. ${ }^{*} p<0.05,{ }^{* * *} p<0.001$, compared to control; Student's $t$-test, $\mathrm{N}=3$.

\subsection{Pharmacological Amelioration of NAF-1 Depletion in INS-1E Cells}

The findings described above reveal that a reduction in NAF-1 protein level in INS$1 \mathrm{E}$ insulinoma cells results in a significant decrease in glucose-stimulated insulin secretion (Figure 1), which was accompanied by structural changes to mitochondria and ER (Figures 2 and 3), as well as a decrease in mitochondrial functions (Figures 4 and 5). Most importantly among these are the enhanced accumulation of $\mathrm{mLI}$ and mROS, which have been directly linked to NAF-1 function in cells $[11,16,18,34]$. Because an increase in mLI can lead to an increase in $\mathrm{mROS}$, which would in turn impact mitochondrial function and structure [14], we tested whether treatments such as chelation of $\mathrm{mLI}$ and/or inhibition of mROS accumulation could ameliorate insulin secretion and mitochondrial and ER morphology of INS-1E NAF-1(-) cells. To test the potential impact of such treatments on pancreatic pathophysiology, we followed $\mathrm{mLI}$, mROS, and stimulated insulin secretion in pancreatic NAF-1(-) cells treated with the membrane permeant iron chelator deferiprone (DFP; $[27,28])$ and the antioxidant glutathione precursor N-acetyl cysteine (NAC; [29-31]), separately and in combination. As shown in Figure 6A,B, treatment with DFP and/or NAC ameliorated the NAF-1(-) induced increase in $\mathrm{mLI}$ and $\mathrm{mROS}$, with the combined application of these two agents having the most significant effect. Although each of these agents significantly improved insulin secretion, their combined action was additively corrective (Figure 6C). In addition to correcting some of the biochemical effects of NAF-1 deficiency (Figure 6), the combined treatment of INS-1E NAF-1(-) cells with DFP+NAC ameliorated the impact of NAF-1 deficiency on mitochondrial and ER morphology (Figure 7). Treatments of INS-1E NAF-1(-) cells with DFP and/or NAC, capable of suppressing ferroptosis [46-48], were therefore able to correct some of the biochemical, morphological, and functional (insulin secretion) phenotypes of NAF-1 deficiency (Figures 6 and 7). 
A
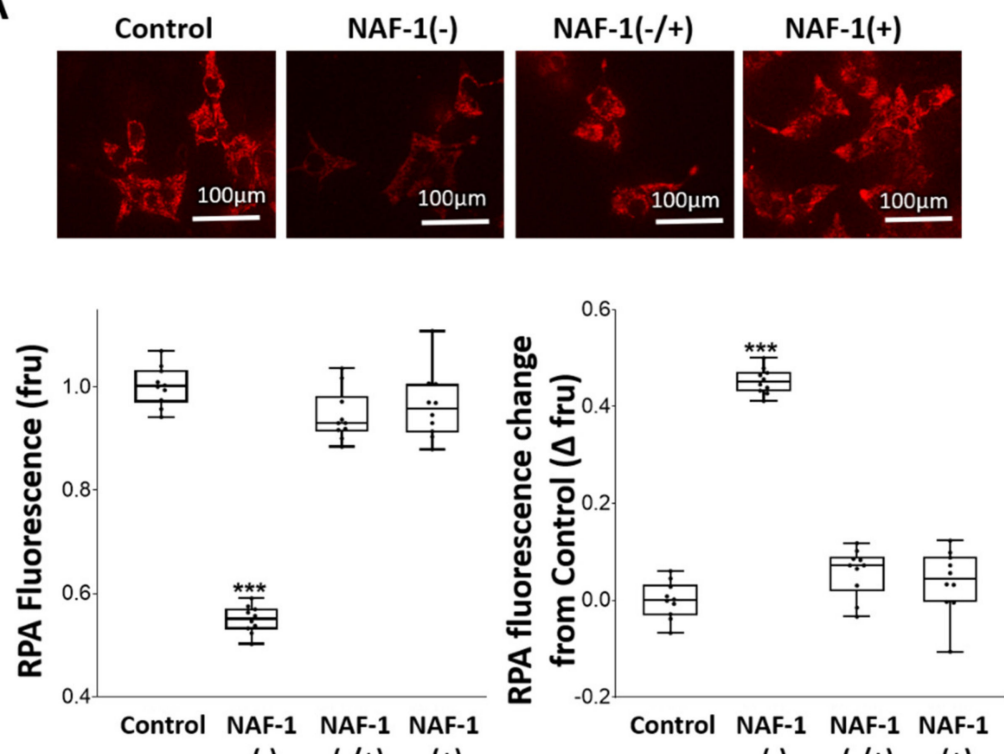

$(-) \quad(-1+) \quad(+)$

$(-) \quad(-/+) \quad(+)$
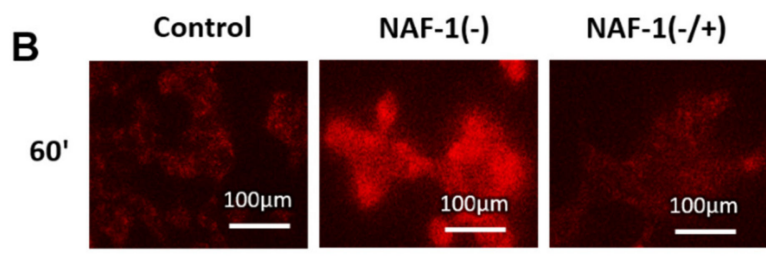

NAF-1(+)
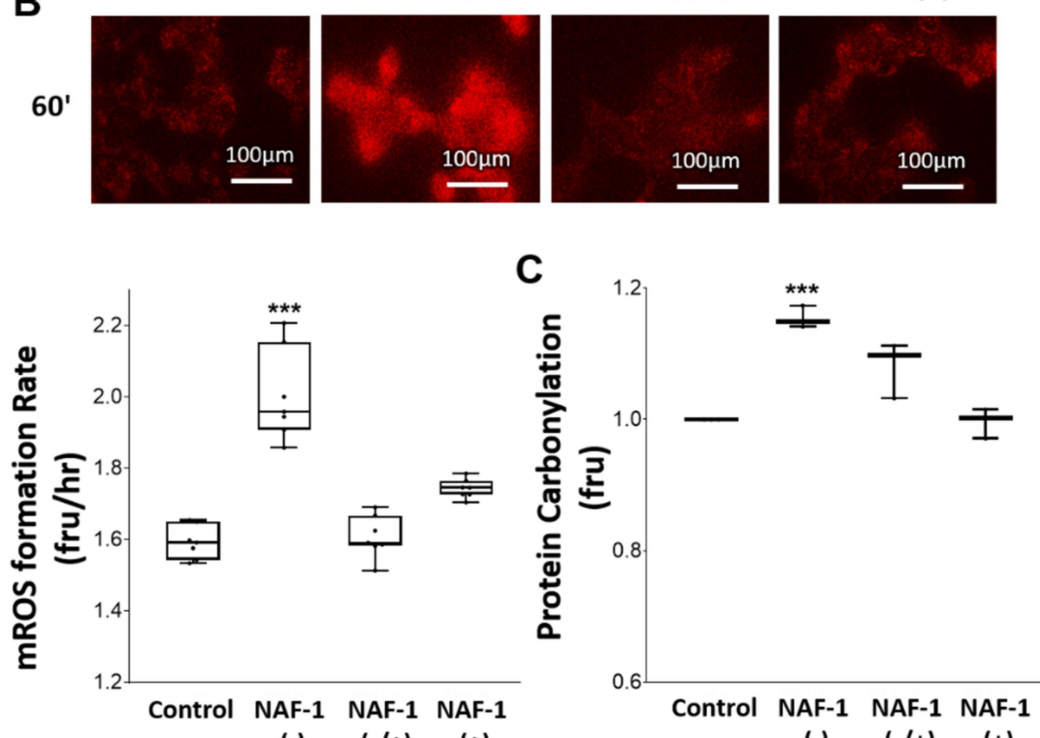

$(-) \quad(-/+) \quad(+)$

$(-) \quad(-/+) \quad(+)$

Figure 5. Mitochondrial labile iron (mLI), ROS (mROS), and protein carbonylation in INS-1E cells with repressed or overexpressed NAF-1 levels. (A) Representative epi-fluorescent images of mitochondrial RPA fluorescence (top), and quantification of mitochondrial RPA fluorescence (bottom graphs) in INS-1E cells with repressed or overexpressed NAF-1 level (left graph is for total RPA fluorescence and right graph is for change in RPA fluorescence from control). Quenching of RPA fluorescence indicates mitochondrial labile iron accumulation. (B) Representative epi-fluorescent images of mitochondrial mito-SOX ${ }^{\mathrm{TM}}$ fluorescence (top), and quantitative analysis (bottom, left), of mitochondrial mito-SOX ${ }^{\mathrm{TM}}$ fluorescence (indicating mitochondrial superoxide accumulation), in INS-1E cells with repressed or overexpressed NAF-1 level. (C) Cellular content of carbonylated proteins in the different INS-1E cell lines with repressed or overexpressed NAF-1 levels, measured with coumarin hydrazine $(\mathrm{CH})$. The results are presented as box-and-whisker plots and include all data points measured from three different experiments. ${ }^{* * *} p<0.001$, compared to control; Student's $t$-test, $\mathrm{N}=450$ for (A), $\mathrm{N}=150$ for (B), and $\mathrm{N}=450$ for (C). 


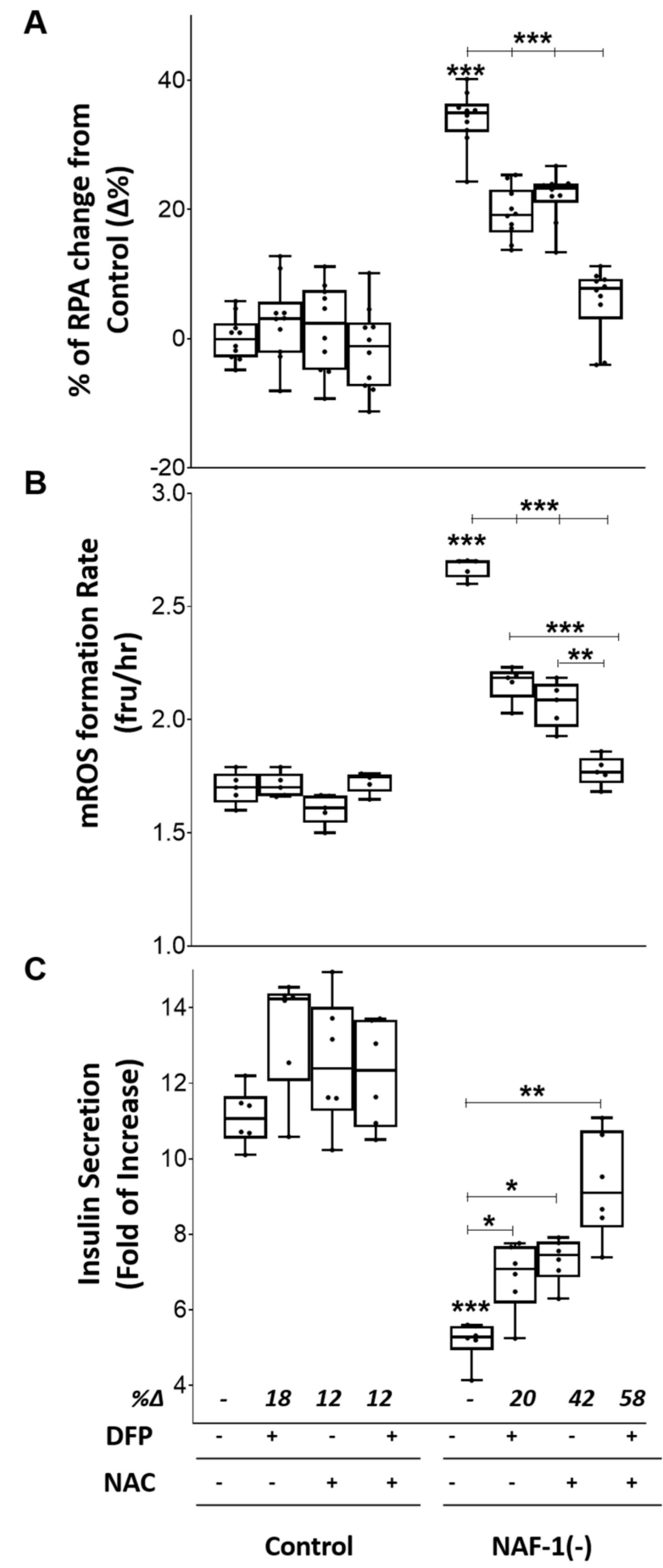

Figure 6. Pharmacological amelioration of enhanced $\mathrm{mLI}$ and $\mathrm{mROS}$, and decrease insulin production in NAF-1(-) INS-1E cells with a combined treatment of DFP and NAC. (A) Mitochondrial labile iron levels in control and NAF-1(-) cells in the presence or absence of DFP $(50 \mu \mathrm{M})$ and / or NAC $(100 \mu \mathrm{M})$. (B) Same as in (A), but for mROS levels. (C) Fold change in glucose-stimulated insulin secretion of control and NAF-1(-) cells in the presence or absence of DFP and/or NAC. The results are shown as box-and-whisker plots and include all data points measured from three different experiments. ${ }^{*} p<0.05,{ }^{* *} p<0.01,{ }^{* * *} p<0.001$, compared to control; Student's $t$-test, $\mathrm{N}=450$ for (A), N = 150 for (B), and $\mathrm{N}=3$ for $(\mathrm{C})$. Abbreviations: DFP, deferiprone; NAC, $\mathrm{N}$ - acetyl cysteine. 
A

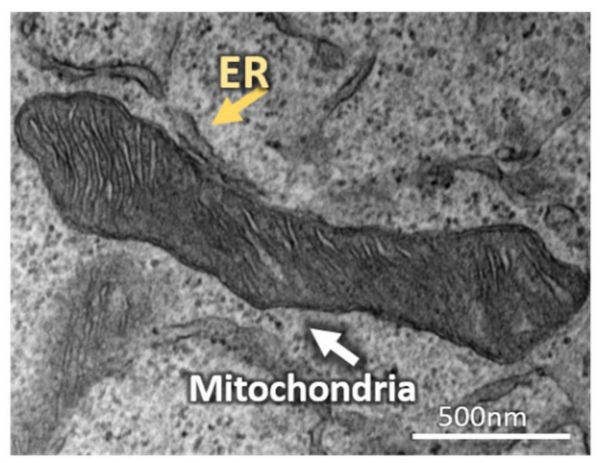

C

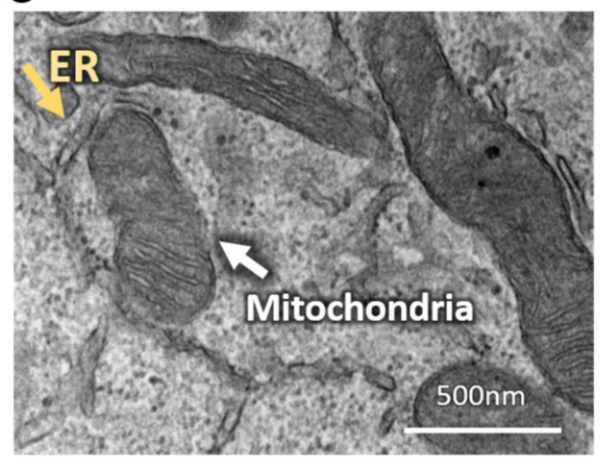

B

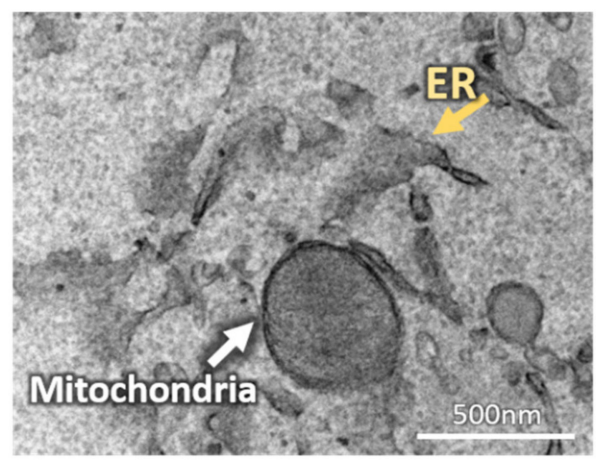

D

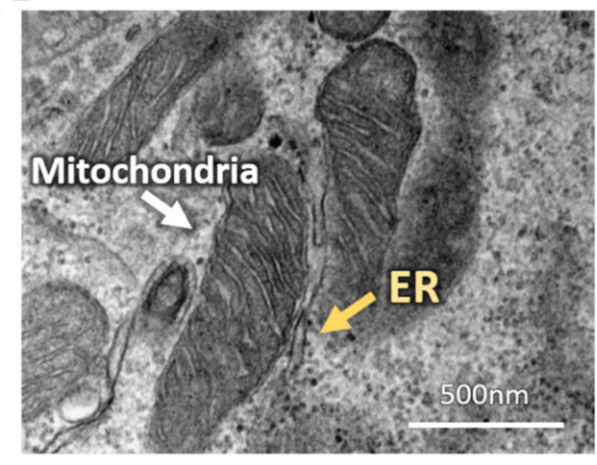

F

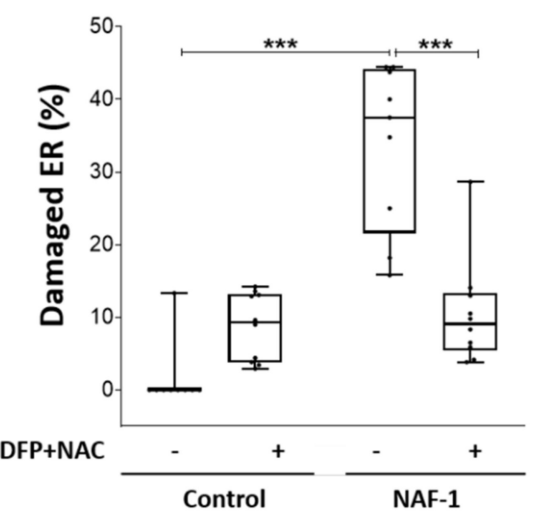

Figure 7. Pharmacological amelioration of mitochondrial and ER morphology in NAF-1(-) INS-1E cells with a combined DFP and NAC treatment. (A-D) Representative TEM images of control and NAF-1(-) INS-1E cells treated or untreated with a NAC $(100 \mu \mathrm{M})+$ DFP $(50 \mu \mathrm{M})$ combination $(\mathrm{A}$, Control. (B) NAF-1(-). (C) Control treated with DFP+ NAC. (D) NAF-1(-) treated with DFP+ NAC). Yellow and white arrows indicate ER and mitochondria, respectively. (E,F) Statistical analysis of mitochondrial (E), or ER (F), damage in NAF-1(-) INS-1E cells following the combined DFP+ NAC treatment. The results are shown as box-and-whisker plots and include all data points measured from three different experiments. ${ }^{* * *} p<0.001$, compared to control; Student's $t$-test, $\mathrm{N}=200$ for mitochondria, $\mathrm{N}=300$ for ER. Abbreviations: DFP, deferiprone; NAC, N-acetyl cysteine.

The rise in $\mathrm{mLI}, \mathrm{mROS}$, and cytosolic $\mathrm{Ca}^{2+}$ levels, upon NAF-1 depletion (Figure 5, Figure S3), and the finding that this rise could be suppressed by treatment with NAC and/or DFP (Figure 6), could suggest that NAF-1 deficiency in insulinoma cells triggers ferroptosis $[49,50]$. To test this possibility, we measured the total levels of reduced glutathione (GSH), the levels of lipid peroxidation, the expression of GPX4 and TfR, and the length of mitochondria in control and NAF-1(-) INS-1E cells. In addition, we studied the 
effect of the ferroptosis inhibitor ferrostatin- $1[25,32,33]$ on these cells. Compared with wildtype, NAF-1(-) cells had lower GSH levels (Figure 8A), enhanced lipid peroxidation (Figure 8B), suppressed expression of GPX4 (Figure 8C), enhanced expression of TfR (Figure 8D), and shortened mitochondria (Figure 8E). By contrast, no apoptosis features such as nuclear degradation were observed in NAF-1(-) cells (Figure 8F). In addition, ferrostatin-1 treatment of INS-1E NAF-1(-) cells resulted in a significant reduction in cellular ROS formation and improved cell growth (Figure 8G). The results presented in Figures 5-8 suggest therefore that NAF-1 deficiency causes the enhanced accumulation of $\mathrm{mLI}$ and $\mathrm{mROS}$ and that this accumulation triggers ferroptosis-like features of INS-1E cells.

A

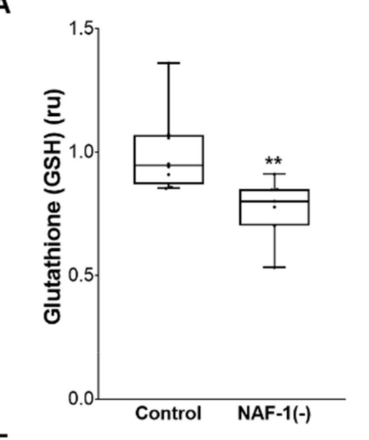

E

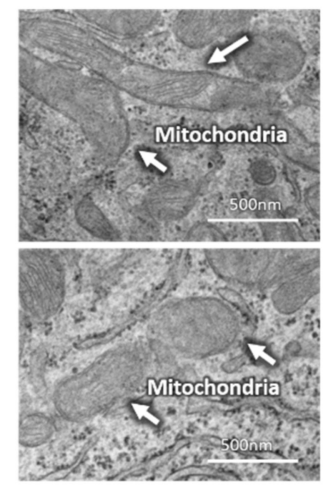

G

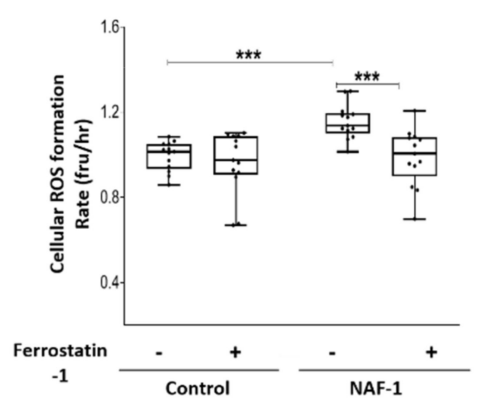

B
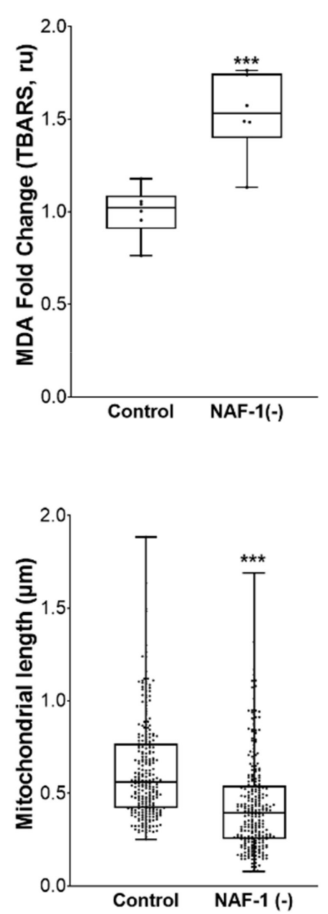

H

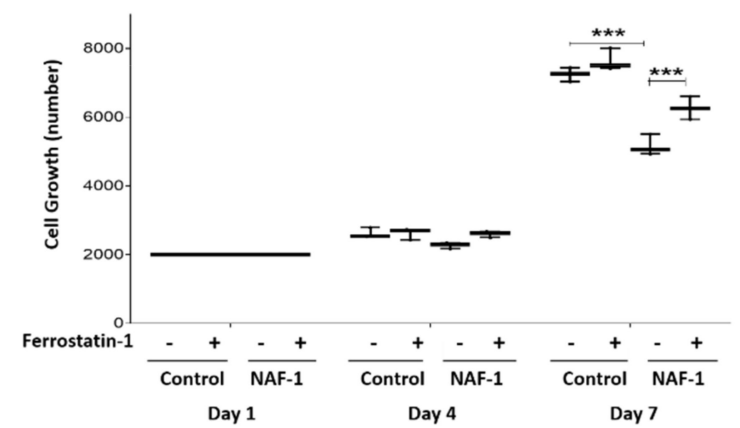

c

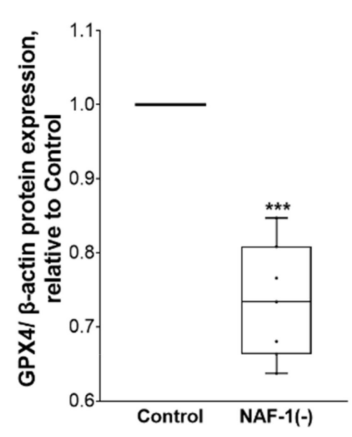

$\mathbf{F}$

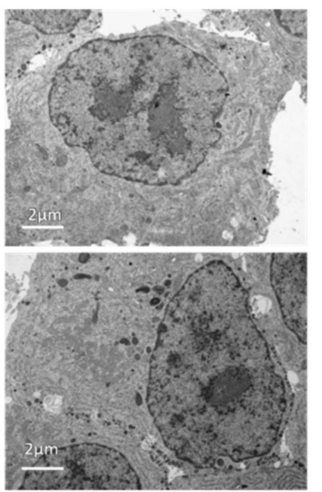

D
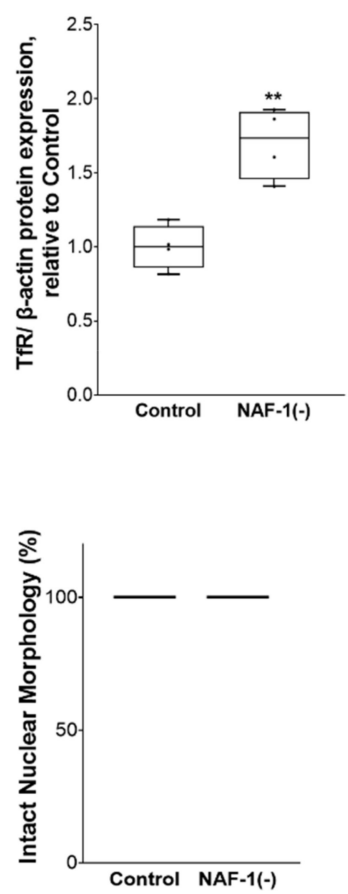

I

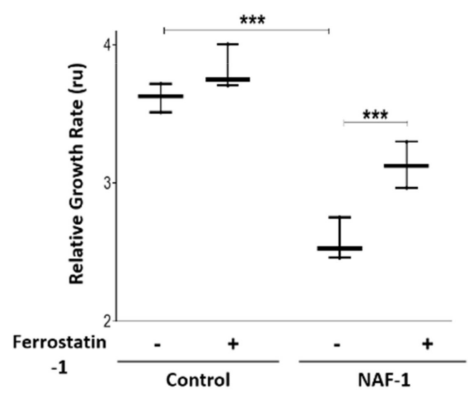

Figure 8. Presence of ferroptosis-like symptoms in NAF-1(-) pancreatic cells. Reduced glutathione (GSH) levels (A), increased lipid peroxidation (B), decreased GPX4 expression (C), enhanced TfR expression (D), and shortened mitochondria (E) (representative image: top, control; bottom, NAF-1-deficient) in control and NAF-1(-) pancreatic cells. (F) Morphology of nuclei in control and NAF-1(-) cells (representative image: top, control; bottom, NAF-1-deficient). (G) Cellular ROS levels in control and NAF-1(-) cells in the presence or absence of $2 \mu \mathrm{M}$, ferrostatin-1. (H,I) cell growth of control and NAF-1(-) cells (measured by counting cell numbers $(\mathbf{H})$ or using PrestoBlue $\left.{ }^{\mathrm{TM}}(\mathrm{I})\right)$ in the presence or absence $2 \mu \mathrm{M}$ ferrostatin-1. The results are shown as box-and-whisker plots and include all data points measured from three different experiments. ${ }^{* *} p<0.01,{ }^{* * *} p<0.001$, compared to control; Student's $t$-test, $N=3$ for $(\mathbf{A}, \mathbf{B}, \mathbf{G}, \mathbf{H}, \mathbf{I}), \mathbf{N}=5$ for (C,D), N = 250 for $(\mathbf{E}), \mathrm{N}=10$ for (F). Abbreviations: GSH, reduced glutathione; MDA, malondialdehyde; GPX4, glutathione peroxidase 4; TfR, transferrin receptor. 


\section{Discussion}

NAF-1 repression or deficiency in animal and cell models results in cellular dyshomeostasis of calcium, [Fe-S] protein functions, iron status, and ROS production $[4,16,34,51]$, as well as in the activation of cell death processes such as apoptosis [12-14,34]. To what extent the changes in cell properties imparted by the experimental repression of NAF-1 fully recapitulate the impaired properties of different tissues found in WFS-T2 patients is still under thorough evaluation. Here, we used the pancreatic INS-1E cellular model system to study how NAF-1 repression impairs insulin secretion in pancreatic cells (Figure 1), recapitulating a key feature of the WFS-T2 phenotype. The repression of NAF-1 induced changes in mitochondrial, ER, and MAM morphology and affected multiple mitochondrial properties (Figures 2-5). First and foremost, we ascertained that it is the actual reduction in NAF-1 per se and not the transfection that led to the changes in the affected cellular properties. This was accomplished by re-expressing wild type NAF-1 in the NAF-1 repressed $\beta$-pancreatic INS-1E cellular model and showing significant restoration of properties affected in mitochondria, ER, and MAM structure-function. These included mitochondrial and ER morphology, mitochondrial labile iron and ROS accumulation, as well as changes in calcium levels, respiration, and insulin secretion (Figures 1-5). Changes in mitochondrial morphology and insulin secretion have previously been shown to result from ROS-induced MMP damage [52], ER stress [53], and an unfolded protein response that can lead to cell death [54]. As MAM and cell $\mathrm{Ca}^{2+}$ have also been implicated in glucose-induced insulin secretion [55], NAF-1 presumed role in regulating subcellular $\mathrm{Ca}^{+2}$ concentrations could take place via putative interactions with the inositol 1,4,5-triphosphate receptor (IP3R) involved in $\mathrm{Ca}^{2+}$ release from the ER [56] and/or sarco/endoplasmic reticulum $\mathrm{Ca}^{2+}$-ATPase (SERCA2) proteins that control $\mathrm{Ca}^{2+}$ fluxes into the ER [57-59].

Aside from NAF-1(-) induced changes in mitochondria-ER MAM integrity (Figures 2 and 3), the multiple changes observed in INS-1E cells upon NAF-1 suppression recapitulate what we and others have observed in previous studies with non-endocrine cells in culture and with animal models of WFS-T2 (i.e., knockouts of NAF-1) [15,60-62]. The novel finding of this work is therefore the establishment of a causative association between NAF-1 repression that leads to a mitochondrial labile iron rise and an increased $\mathrm{mROS}$ formation that triggers ferroptosis, and the impairment of $\beta$-cell insulin secretion. This association was experimentally demonstrated by the combined application of the mitochondrial iron chelator DFP and the GSH precursor NAC (Figures 6 and 7), as well as by the application of the ferroptosis inhibitor ferrostatin-1 [63] (Figure 8). First, we show that reduced GSH levels were significantly decreased in NAF-1(-) cells, possibly explaining the increased mROS formation that could also be attenuated by DFP+NAC, a combined treatment known to reduce these two arms of ferroptosis $[49,50]$. We further show that suppressed NAF-1 expression results in enhanced lipid peroxidation, suppressed expression of GPX4, enhanced expression of TfR, and the appearance of smaller mitochondria (Figure 8), all classic hallmarks of ferroptosis [64]. GSH may also have a role in iron homeostasis in addition to its antioxidant redox buffer effects $[65,66]$. Moreover, the combined DFP and NAC treatment of pancreatic INS-1E NAF-1(-) cells led to a significant amelioration of mLI and mROS, as well as enhanced insulin secretion and improved mitochondria and ER morphologies (Figures 6 and 7), which are some of the hallmarks of WFS-T2 [11,60]. Although the use of low levels of DFP was previously shown to cause enhanced accumulation of ROS in cancer cells [67,68], the concentrations used in our study were much higher. These concentrations were previously shown to also suppress ROS formation in cancer cells $[16,69]$ and are acceptable for the application of DFP in other systems [70,71]. Pending additional studies conducted using different cell lines, as well as different model organisms, our findings could provide a novel rationale for pharmacological intervention for symptomatic improvement in an otherwise incurable disease.

\section{Conclusions}

Currently, it is clinically impractical to change the whole-body intracellular expression levels of NAF-1 in vivo in WFS-T2 patients. Here, we succeeded in alleviating the abnormalities caused by NAF-1 reduction using a pharmacological approach (DFP+NAC). 
The combined DFP and NAC treatment of pancreatic INS-1E NAF-1(-) cells repaired to near-normal levels the abnormalities in mLI and mROS accumulation, mitochondrial and ER morphologies, and insulin secretion. These findings suggested that ferroptosis could be playing an important role in WFS-T2 $\beta$-pancreatic pathophysiology, supported by the correcting effect of ferrostatin- 1 on cellular growth as well as cellular ROS generation of INS-1E NAF-1(-) cells. Our findings suggest therefore that targeting ferroptosis of pancreatic cells, for example, by the combined pharmacological application of the clinically approved DFP and NAC, could be used as a viable strategy in the treatment of WFS-T2 patients and perhaps patients suffering from other metabolic diseases that result in enhanced $\mathrm{mLI}$ and mROS levels [72-76].

Supplementary Materials: The following are available online at https:/ /www.mdpi.com/article/10 .3390/antiox10081160/s1.

Author Contributions: Conceptualization: I.Z.C., R.N. and R.M. Experimental Design: O.K., G.L., Y.N., I.Z.C., R.N. and R.M. Data collection: O.K., Y.-S.S., H.-B.M., T.I. and K.I. Methodology: O.K., I.Z.C. and R.N. Data curation: O.K. Formal analysis: O.K. Funding acquisition: R.M. and R.N. Wrote the manuscript: O.K., I.Z.C., R.N. and R.M. All authors have read and agreed to the published version of the manuscript.

Funding: O.K. acknowledges the Annual Golda Meir Fellowship and the Hebrew University Rector for the Emergency Scholarship recipients for Postdoctoral fellows, 2020-2021. This work was supported by the NSF-Binational Science Foundation (BSF) Grant NSF-MCB 1613462 (to R.M.) and BSF Grant 2015831 (to R.N.). Support for this study was also provided by NIDDK DK120986 (K.P.M.), DK101753 (K.P.M.), DK114464 (K.P.M.), and GM111364 (to R.M.).

Institutional Review Board Statement: Not applicable.

Informed Consent Statement: Not applicable.

Data Availability Statement: Data is contained within the article and Supplementary Materials.

Conflicts of Interest: The authors declare no conflict of interest.

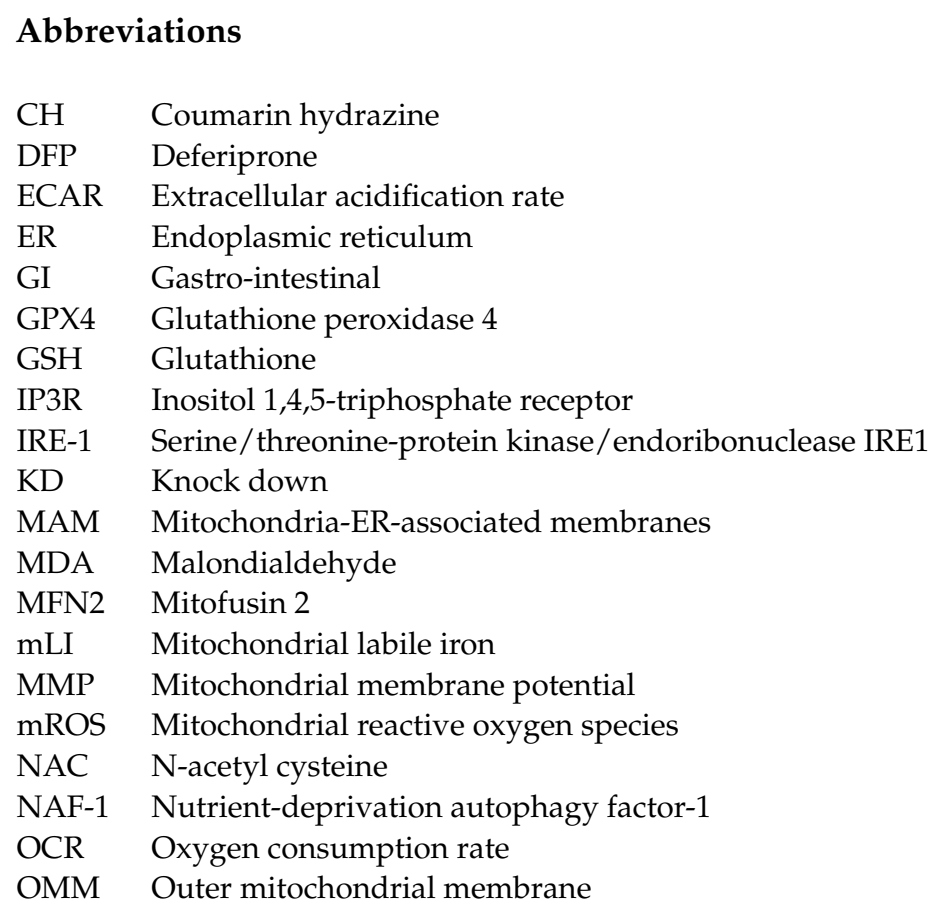




$\begin{array}{ll}\text { ROS } & \text { Reactive oxygen species } \\ \text { RPA } & \text { Rhodamine B-[(1,10-phenanthrolin-5-yl) aminocarbonyl] benzyl ester } \\ \text { SERCA2 } & \text { Sarco/endoplasmic reticulum Ca2+-ATPase } \\ \text { TBARS } & \text { Thiobarbituric acid reactive substances } \\ \text { TEM } & \text { Transmission electron microscope } \\ \text { TfR } & \text { Transferrin receptor } \\ \text { TMRE } & \text { Tetramethylrhodamine ethyl ester } \\ \text { TRX } & \text { Thioredoxin } \\ \text { TXNIP } & \text { Thioredoxin-interacting protein } \\ \text { UPR } & \text { Unfolded protein response } \\ \text { WFS-T2 } & \text { Wolfram syndrome type } 2 \\ \text { WT } & \text { Wildtype }\end{array}$

\section{References}

1. Amr, S.; Heisey, C.; Zhang, M.; Xia, X.-J.; Shows, K.H.; Ajlouni, K.; Pandya, A.; Satin, L.S.; El-Shanti, H.; Shiang, R. A Homozygous Mutation in a Novel Zinc-Finger Protein, ERIS, Is Responsible for Wolfram Syndrome 2. Am. J. Hum. Genet. 2007, 81, 673-683. [CrossRef]

2. Mozzillo, E.; Delvecchio, M.; Carella, M.; Grandone, E.; Palumbo, P.; Salina, A.; Aloi, C.; Buono, P.; Izzo, A.; D'Annunzio, G.; et al. A novel CISD2 intragenic deletion, optic neuropathy and platelet aggregation defect in Wolfram syndrome type 2 . BMC Med. Genet. 2014, 15, 88. [CrossRef]

3. Rondinelli, M.; Novara, F.; Calcaterra, V.; Zuffardi, O.; Genovese, S. Wolfram syndrome 2: A novel CISD2 mutation identified in Italian siblings. Acta Diabetol. 2015, 52, 175-178. [CrossRef]

4. Rouzier, C.; Moore, D.; Delorme, C.; Lacas-Gervais, S.; Ait-El-Mkadem, S.; Fragaki, K.; Burté, F.; Serre, V.; Bannwarth, S.; Chaussenot, A.; et al. A novel CISD2 mutation associated with a classical Wolfram syndrome phenotype alters Ca2+ homeostasis and ER-mitochondria interactions. Hum. Mol. Genet. 2017, 26, 1599-1611. [CrossRef] [PubMed]

5. Akturk, H.K.; Msc, S.Y. Previously unreported abnormalities in Wolfram Syndrome Type 2. Pediatr. Endocrinol. Diabetes Metab. 2017, 23, 107-110. [CrossRef] [PubMed]

6. Cattaneo, M.; La Sala, L.; Rondinelli, M.; Errichiello, E.; Zuffardi, O.; Puca, A.A.; Genovese, S.; Ceriello, A. A donor splice site mutation in CISD2 generates multiple truncated, non-functional isoforms in Wolfram syndrome type 2 patients. BMC Med. Genet. 2017, 18, 147. [CrossRef]

7. Pourreza, M.R.; Sobhani, M.; Rahimi, A.; Aramideh, M.; Kajbafzadeh, A.-M.; Noori-Daloii, M.R.; Tabatabaiefar, M.A. Homozygosity mapping and direct sequencing identify a novel pathogenic variant in the CISD2 gene in an Iranian Wolfram syndrome family. Acta Diabetol. 2020, 57, 81-87. [CrossRef] [PubMed]

8. Ajlouni, K.; Jarrah, N.; El-Khateeb, M.; El-Zaheri, M.; El-Shanti, H.; Lidral, A. Wolfram syndrome: Identification of a phenotypic and genotypic variant from Jordan. Am. J. Med. Genet. 2002, 115, 61-65. [CrossRef]

9. Rigoli, L.; Di Bella, C. Wolfram syndrome 1 and Wolfram syndrome 2. Curr. Opin. Pediatr. 2012, 24, 512-517. [CrossRef] [PubMed]

10. Urano, F. Wolfram Syndrome: Diagnosis, Management, and Treatment. Curr. Diabetes Rep. 2016, 16, 1-8. [CrossRef] [PubMed]

11. Danielpur, L.; Sohn, Y.-S.; Karmi, O.; Fogel, C.; Zinger, A.; Abu-Libdeh, A.; Israeli, T.; Riahi, Y.; Pappo, O.; Birk, R.; et al. GLP-1-RA Corrects Mitochondrial Labile Iron Accumulation and Improves $\beta$-Cell Function in Type 2 Wolfram Syndrome. J. Clin. Endocrinol. Metab. 2016, jc20162240. [CrossRef] [PubMed]

12. Tamir, S.; Paddock, M.L.; Darash-Yahana-Baram, M.; Holt, S.H.; Sohn, Y.S.; Agranat, L.; Michaeli, D.; Stofleth, J.; Lipper, C.H.; Morcos, F.; et al. Structure-function analysis of NEET proteins uncovers their role as key regulators of iron and ROS homeostasis in health and disease. Biochim. Biophys. Acta 2015, 1853, 1294-1315. [CrossRef]

13. Karmi, O.; Marjault, H.-B.; Pesce, L.; Carloni, P.; Onuchic, J.N.; Jennings, P.A.; Mittler, R.; Nechushtai, R. The unique fold and lability of the $[2 \mathrm{Fe}-2 \mathrm{~S}]$ clusters of NEET proteins mediate their key functions in health and disease. JBIC J. Biol. Inorg. Chem. 2018, 23, 599-612. [CrossRef]

14. Mittler, R.; Darash-Yahana, M.; Sohn, Y.S.; Bai, F.; Song, L.; Cabantchik, I.Z.; Jennings, P.A.; Onuchic, J.N.; Nechushtai, R. NEET Proteins: A New Link Between Iron Metabolism, Reactive Oxygen Species, and Cancer. Antioxid. Redox Signal 2019, 30, 1083-1095. [CrossRef]

15. Nechushtai, R.; Karmi, O.; Zuo, K.; Marjault, H.-B.; Darash-Yahana, M.; Sohn, Y.-S.; King, S.D.; Zandalinas, S.I.; Carloni, P.; Mittler, R. The balancing act of NEET proteins: Iron, ROS, calcium and metabolism. Biochim. Biophys. Acta (BBA) Mol. Cell Res. 2020, 1867, 118805. [CrossRef]

16. Sohn, Y.-S.; Tamir, S.; Song, L.; Michaeli, D.; Matouk, I.; Conlan, A.R.; Harir, Y.; Holt, S.H.; Shulaev, V.; Paddock, M.L.; et al. NAF-1 and mitoNEET are central to human breast cancer proliferation by maintaining mitochondrial homeostasis and promoting tumor growth. Proc. Natl. Acad. Sci. USA 2013, 110, 14676-14681. [CrossRef] [PubMed]

17. Liu, L.; Xia, M.; Wang, J.; Zhang, W.; Zhang, Y.; He, M. CISD2 expression is a novel marker correlating with pelvic lymph node metastasis and prognosis in patients with early-stage cervical cancer. Med. Oncol. 2014, 31, 1-12. [CrossRef] [PubMed] 
18. Darash-Yahana, M.; Pozniak, Y.; Lu, M.; Sohn, Y.-S.; Karmi, O.; Tamir, S.; Bai, F.; Song, L.; Jennings, P.A.; Pikarsky, E.; et al. Breast cancer tumorigenicity is dependent on high expression levels of NAF-1 and the lability of its Fe-S clusters. Proc. Natl. Acad. Sci. USA 2016, 113, 10890-10895. [CrossRef]

19. Yang, L.; Hong, S.; Wang, Y.; He, Z.; Liang, S.; Chen, H.; He, S.; Wu, S.; Song, L.; Chen, Y. A novel prognostic score model incorporating CDGSH iron sulfur domain2 (CISD2) predicts risk of disease progression in laryngeal squamous cell carcinoma. Oncotarget 2016, 7, 22720-22732. [CrossRef]

20. Wang, L.; Ouyang, F.; Liu, X.; Wu, S.; Wu, H.-M.; Xu, Y.; Wang, B.; Zhu, J.; Xu, X.; Zhang, L. Overexpressed CISD2 has prognostic value in human gastric cancer and promotes gastric cancer cell proliferation and tumorigenesis via AKT signaling pathway. Oncotarget 2016, 7, 3791-3805. [CrossRef]

21. Li, S.-M.; Chen, C.-H.; Chen, Y.-W.; Yen, Y.-C.; Fang, W.-T.; Tsai, F.-Y.; Chang, J.-L.; Shen, Y.-Y.; Huang, S.-F.; Chuu, C.-P.; et al. Upregulation of CISD2 augments ROS homeostasis and contributes to tumorigenesis and poor prognosis of lung adenocarcinoma. Sci. Rep. 2017, 7, 11893. [CrossRef] [PubMed]

22. Sun, Y.; Jiang, Y.; Huang, J.; Chen, H.; Liao, Y.; Yang, Z. CISD2 enhances the chemosensitivity of gastric cancer through the enhancement of 5-FU-induced apoptosis and the inhibition of autophagy by AKT/mTOR pathway. Cancer Med. 2017, 6, 2331-2346. [CrossRef]

23. Sun, A.-G.; Meng, F.-G.; Wang, M.-G. CISD2 promotes the proliferation of glioma cells via suppressing beclin-1-mediated autophagy and is targeted by microRNA-449a. Mol. Med. Rep. 2017, 16, 7939-7948. [CrossRef] [PubMed]

24. Kim, E.H.; Shin, D.; Lee, J.; Jung, A.R.; Roh, J.-L. CISD2 inhibition overcomes resistance to sulfasalazine-induced ferroptotic cell death in head and neck cancer. Cancer Lett. 2018, 432, 180-190. [CrossRef]

25. Yuan, H.; Li, X.; Zhang, X.; Kang, R.; Tang, D. CISD1 inhibits ferroptosis by protection against mitochondrial lipid peroxidation. Biochem. Biophys. Res. Commun. 2016, 478, 838-844. [CrossRef] [PubMed]

26. Furihata, T.; Takada, S.; Kakutani, N.; Maekawa, S.; Tsuda, M.; Matsumoto, J.; Mizushima, W.; Fukushima, A.; Yokota, T.; Enzan, N.; et al. Cardiac-specific loss of mitoNEET expression is linked with age-related heart failure. Commun. Biol. 2021, 4, 1-11. [CrossRef]

27. Pandolfo, M.; Hausmann, L. Deferiprone for the treatment of Friedreich's ataxia. J. Neurochem. 2013, 126, 142-146. [CrossRef]

28. Agrawal, S.; Fox, J.; Thyagarajan, B.; Fox, J.H. Brain mitochondrial iron accumulates in Huntington's disease, mediates mitochondrial dysfunction, and can be removed pharmacologically. Free. Radic. Biol. Med. 2018, 120, 317-329. [CrossRef]

29. Wongjaikam, S.; Kumfu, S.; Khamseekaew, J.; Chattipakorn, S.C.; Chattipakorn, N. Restoring the impaired cardiac calcium homeostasis and cardiac function in iron overload rats by the combined deferiprone and N-acetyl cysteine. Sci. Rep. 2017, 7, srep44460. [CrossRef]

30. Mohammadi, H.; Sayad, A.; Mohammadi, M.; Niknahad, H.; Heidari, R. N-acetyl cysteine treatment pre-serves mitochondrial indices of functionality in the brain of hyperammonemic mice. Clin. Exp. Hepatol. 2020, 6, 106. [CrossRef]

31. Ommati, M.M.; Amjadinia, A.; Mousavi, K.; Azarpira, N.; Jamshidzadeh, A.; Heidari, R. N-acetyl cysteine treatment mitigates biomarkers of oxidative stress in different tissues of bile duct ligated rats. Stress 2021, 24, 213-228. [CrossRef]

32. Anthonymuthu, T.S.; Tyurina, Y.Y.; Sun, W.-Y.; Mikulska-Ruminska, K.; Shrivastava, I.H.; Tyurin, V.A.; Cinemre, F.B.; Dar, H.H.; VanDemark, A.P.; Holman, T.R.; et al. Resolving the paradox of ferroptotic cell death: Ferrostatin-1 binds to 15LOX/PEBP1 complex, suppresses generation of peroxidized ETE-PE, and protects against ferroptosis. Redox Biol. 2021, 38, 101744. [CrossRef] [PubMed]

33. Liu, P.; Feng, Y.; Li, H.; Chen, X.; Wang, G.; Xu, S.; Li, Y.; Zhao, L. Ferrostatin-1 alleviates lipopolysaccharide-induced acute lung injury via inhibiting ferroptosis. Cell. Mol. Biol. Lett. 2020, 25, 1-14. [CrossRef] [PubMed]

34. Holt, S.H.; Darash-Yahana, M.; Sohn, Y.S.; Song, L.; Karmi, O.; Tamir, S.; Michaeli, D.; Luo, Y.; Paddock, M.L.; Jennings, P.A.; et al. Activation of apoptosis in NAF-1-deficient human epithelial breast cancer cells. J. Cell Sci. 2016, 129, 155-165. [CrossRef] [PubMed]

35. Mukherjee, K.; Chio, T.I.; Sackett, D.L.; Bane, S.L. Detection of oxidative stress-induced carbonylation in live mammalian cells. Free. Radic. Biol. Med. 2015, 84, 11-21. [CrossRef]

36. Bharath, S.; Hsu, M.; Kaur, D.; Rajagopalan, S.; Andersen, J.K. Glutathione, iron and Parkinson's disease. Biochem. Pharmacol. 2002, 64, 1037-1048. [CrossRef]

37. Lu, S.C. Regulation of glutathione synthesis. Mol. Asp. Med. 2009, 30, 42-59. [CrossRef] [PubMed]

38. Schieber, M.; Chandel, N.S. ROS Function in Redox Signaling and Oxidative Stress. Curr. Biol. 2014, 24, R453-R462. [CrossRef]

39. Divakaruni, A.S.; Paradyse, A.; Ferrick, D.A.; Murphy, A.N.; Jastroch, M. Analysis and Interpretation of Microplate-Based Oxygen Consumption and pH Data. In Methods in Enzymology; Elsevier BV: Amsterdam, The Netherlands, 2014; Volume 547, pp. 309-335. [CrossRef]

40. Xu, W.; Li, T.; Gao, L.; Zheng, J.; Yan, J.; Zhang, J.; Shao, A. Apelin-13/APJ system attenuates early brain injury via suppression of endoplasmic reticulum stress-associated TXNIP/NLRP3 inflammasome activation and oxidative stress in a AMPK-dependent manner after subarachnoid hemorrhage in rats. J. Neuroinflamm. 2019, 16, 1-14. [CrossRef]

41. Yoshihara, E.; Masaki, S.; Matsuo, Y.; Chen, Z.; Tian, H.; Yodoi, J. Thioredoxin/Txnip: Redoxisome, as a Redox Switch for the Pathogenesis of Diseases. Front. Immunol. 2013, 4, 514. [CrossRef]

42. Zhou, R.; Tardivel, A.; Thorens, B.; Choi, I.; Tschopp, J. Thioredoxin-interacting protein links oxidative stress to inflammasome activation. Nat. Immunol. 2010, 11, 136-140. [CrossRef] 
43. Schrepfer, E.; Scorrano, L. Mitofusins, from Mitochondria to Metabolism. Mol. Cell 2016, 61, 683-694. [CrossRef]

44. De Brito, O.M.; Scorrano, L. Mitofusin-2 regulates mitochondrial and endoplasmic reticulum morphology and tethering: The role of Ras. Mitochondrion 2009, 9, 222-226. [CrossRef] [PubMed]

45. Naon, D.; Zaninello, M.; Giacomello, M.; Varanita, T.; Grespi, F.; Lakshminaranayan, S.; Serafini, A.; Semenzato, M.; Herkenne, S.; Hernández-Alvarez, M.I.; et al. Critical reappraisal confirms that Mitofusin 2 is an endoplasmic reticulum-mitochondria tether. Proc. Natl. Acad. Sci. USA 2016, 113, 11249-11254. [CrossRef]

46. Abdalkader, M.; Lampinen, R.; Kanninen, K.M.; Malm, T.; Liddell, J.R. Targeting Nrf2 to Suppress Ferroptosis and Mitochondrial Dysfunction in Neurodegeneration. Front. Neurosci. 2018, 12, 466. [CrossRef] [PubMed]

47. Codenotti, S.; Poli, M.; Asperti, M.; Zizioli, D.; Marampon, F.; Fanzani, A. Cell growth potential drives ferroptosis susceptibility in rhabdomyosarcoma and myoblast cell lines. J. Cancer Res. Clin. Oncol. 2018, 144, 1717-1730. [CrossRef] [PubMed]

48. Chen, J.; Wang, Y.; Wu, J.; Yang, J.; Li, M.; Chen, Q. The Potential Value of Targeting Ferroptosis in Early Brain Injury After Acute CNS Disease. Front. Mol. Neurosci. 2020, 13, 110. [CrossRef] [PubMed]

49. Yuan, H.; Pratte, J.; Giardina, C. Ferroptosis and its potential as a therapeutic target. Biochem. Pharmacol. 2021, 186, 114486. [CrossRef]

50. Li, Z.-J.; Dai, H.-Q.; Huang, X.-W.; Feng, J.; Deng, J.-H.; Wang, Z.-X.; Yang, X.-M.; Liu, Y.-J.; Wu, Y.; Chen, P.-H.; et al. Artesunate synergizes with sorafenib to induce ferroptosis in hepatocellular carcinoma. Acta Pharmacol. Sin. 2021, 42, 301-310. [CrossRef]

51. Wang, C.-H.; Chen, Y.-F.; Wu, C.-Y.; Wu, P.-C.; Huang, Y.-L.; Kao, C.-H.; Lin, C.-H.; Kao, L.-S.; Tsai, T.-F.; Wei, Y.-H. Cisd2 modulates the differentiation and functioning of adipocytes by regulating intracellular Ca2+ homeostasis. Hum. Mol. Genet. 2014, 23, 4770-4785. [CrossRef]

52. Chen, J.; Stimpson, S.; Fernandez-Bueno, G.A.; Mathews, C.E. Mitochondrial Reactive Oxygen Species and Type 1 Diabetes. Antioxid. Redox Signal. 2018, 29, 1361-1372. [CrossRef] [PubMed]

53. Brozzi, F.; Eizirik, D.L. ER stress and the decline and fall of pancreatic beta cells in type 1 diabetes. Upsala J. Med. Sci. 2016, 121, 133-139. [CrossRef] [PubMed]

54. Lerner, A.G.; Upton, J.-P.; Praveen, P.; Ghosh, R.; Nakagawa, Y.; Igbaria, A.; Shen, S.; Nguyen, V.; Backes, B.J.; Heiman, M.; et al. IRE1 $\alpha$ Induces Thioredoxin-Interacting Protein to Activate the NLRP3 Inflammasome and Promote Programmed Cell Death under Irremediable ER Stress. Cell Metab. 2012, 16, 250-264. [CrossRef] [PubMed]

55. Rutter, G.; Pinton, P. Mitochondria-associated endoplasmic reticulum membranes in insulin signaling. Diabetes 2014, 63, 3163-3165. [CrossRef] [PubMed]

56. Chang, N.C.; Nguyen, M.; Germain, M.; Shore, G.C. Antagonism of Beclin 1-dependent autophagy by BCL-2 at the endoplasmic reticulum requires NAF-1. EMBO J. 2009, 29, 606-618. [CrossRef] [PubMed]

57. Shen, Z.-Q.; Chen, Y.-F.; Chen, J.-R.; Jou, Y.-S.; Wu, P.-C.; Kao, C.-H.; Wang, C.-H.; Huang, Y.-L.; Chen, C.-F.; Huang, T.-S.; et al. CISD2 Haploinsufficiency Disrupts Calcium Homeostasis, Causes Nonalcoholic Fatty Liver Disease, and Promotes Hepatocellular Carcinoma. Cell Rep. 2017, 21, 2198-2211. [CrossRef] [PubMed]

58. Shen, Z.-Q.; Huang, Y.-L.; Tsai, T.-F. Cisd2 haploinsufficiency: A driving force for hepatocellular carcinoma. Mol. Cell. Oncol. 2018, 5, e1441627. [CrossRef]

59. Rutter, G.A.; Tsuboi, T.; Ravier, M. Ca2+ microdomains and the control of insulin secretion. Cell Calcium 2006, 40, 539-551. [CrossRef] [PubMed]

60. Wiley, S.E.; Andreyev, A.Y.; Divakaruni, A.S.; Karisch, R.; Perkins, G.; Wall, E.A.; van der Geer, P.; Chen, Y.F.; Tsai, T.F.; Simon, M.I.; et al. Wolfram Syndrome protein, Miner1, regulates sulphydryl redox status, the unfolded protein response, and $\mathrm{Ca}^{2+}$ homeostasis. EMBO Mol. Med. 2013, 5, 904-918. [CrossRef]

61. Shen, Z.-Q.; Huang, Y.-L.; Teng, Y.-C.; Wang, T.-W.; Kao, C.-H.; Yeh, C.-H.; Tsai, T.-F. CISD2 maintains cellular homeostasis. Biochim. Biophys. Acta (BBA) Mol. Cell Res. 2021, 1868, 118954. [CrossRef]

62. Delprat, B.; Maurice, T.; Delettre, C. Wolfram syndrome: MAMs' connection? Cell Death Dis. 2018, 9, 1-13. [CrossRef]

63. Sun, Y.; Zheng, Y.; Wang, C.; Liu, Y. Glutathione depletion induces ferroptosis, autophagy, and premature cell senescence in retinal pigment epithelial cells. Cell Death Dis. 2018, 9, 1-15. [CrossRef]

64. Li, J.; Cao, F.; Yin, H.-1.; Huang, Z.-j.; Lin, Z.-t.; Mao, N.; Sun, B.; Wang, G. Ferroptosis: Past, present and future. Cell Death Disease 2020, 11, 1-13. [CrossRef]

65. Berndt, C.; Lillig, C.H. Glutathione, Glutaredoxins, and Iron. Antioxid. Redox Signal. 2017, 27, 1235-1251. [CrossRef] [PubMed]

66. Yang, W.S.; SriRamaratnam, R.; Welsch, M.E.; Shimada, K.; Skouta, R.; Viswanathan, V.; Cheah, J.H.; Clemons, P.A.; Shamji, A.F.; Clish, C.; et al. Regulation of Ferroptotic Cancer Cell Death by GPX4. Cell 2014, 156, 317-331. [CrossRef]

67. Yu, Y.; Gutierrez, E.; Kovacevic, Z.; Saletta, F.; Obeidy, P.; Rahmanto, Y.S.; Richardson, D. Iron Chelators for the Treatment of Cancer. Curr. Med. Chem. 2012, 19, 2689-2702. [CrossRef] [PubMed]

68. Fiorillo, M.; Tóth, F.; Brindisi, M.; Sotgia, F.; Lisanti, M.P. Deferiprone (DFP) Targets Cancer Stem cell (CSC) Propagation by Inhibiting Mitochondrial Metabolism and Inducing ROS Production. Cells 2020, 9, 1529. [CrossRef]

69. Buss, J.L.; Greene, B.T.; Turner, J.; Torti, F.M.; Torti, S.V. Iron chelators in cancer chemotherapy. Curr. Top. Med. Chem. 2004, 4, 1623-1635. [CrossRef]

70. Merkofer, M.; Kissner, R.; Hider, R.C.; Brunk, U.T.; Koppenol, W.H. Fenton Chemistry and Iron Chelation under Physiologically Relevant Conditions: Electrochemistry and Kinetics. Chem. Res. Toxicol. 2006, 19, 1263-1269. [CrossRef] 
71. Kuo, K.; Mrkobrada, M. A Systematic Review and Meta-Analysis of Deferiprone Monotherapy and in Combination with Deferoxamine for Reduction of Iron Overload in Chronically Transfused Patients with $\beta$-Thalassemia. Hemoglobin 2014, 38, 409-421. [CrossRef]

72. Fernández-Real, J.M.; López-Bermejo, A.; Ricart, W. Cross-Talk Between Iron Metabolism and Diabetes. Diabetes 2002, 51, 2348-2354. [CrossRef]

73. Stroh, M.; Swerdlow, R.H.; Zhu, H. Common defects of mitochondria and iron in neurodegeneration and diabetes (MIND): A paradigm worth exploring. Biochem. Pharmacol. 2014, 88, 573-583. [CrossRef] [PubMed]

74. Swaminathan, S.; Fonseca, V.A.; Alam, M.G.; Shah, S.V. The Role of Iron in Diabetes and Its Complications. Diabetes Care 2007, 30, 1926-1933. [CrossRef] [PubMed]

75. Wachnowsky, C.; Fidai, I.; Cowan, J.A. Iron-sulfur cluster biosynthesis and trafficking-impact on human disease conditions. Metallomics 2018, 10, 9-29. [CrossRef] [PubMed]

76. Petronek, M.S.; Spitz, D.R.; Buettner, G.R.; Allen, B.G. Linking Cancer Metabolic Dysfunction and Genetic Instability through the Lens of Iron Metabolism. Cancers 2019, 11, 1077. [CrossRef] 